\title{
Violence and Human Development
}

\author{
By Elton B. MCNeIL
}

ABstract: For centuries, mankind has watched, helplessly, as his capacity for planetary destruction has outdistanced his ability to comprehend the reasons for human violence. In desperation, man has scoured the animal kingdom searching for a model of comportment, and he has returned, emptyhanded, from his quest. Psychology has insisted that it has a clue to the crude recipe for the creation of violent individuals and that the analysis of violence at a personal, group, national, or international level must focus on the nature of the developing human being who will---by happenstance or cold designsucceed to a position of leadership. The psychological structure of the leader and of his lieutenants is a vital piece of the puzzle of violence both at the juvenile resort-riot level and in the game of cold war-hot war bluff. Without an increased understanding of the forces that shape the individual, we will forever fail to comprehend the direction that international violence may take.

Elton B. McNeil, Ph.D., Ann Arbor, Michigan, is Professor of Psychology and Chairman of Graduate Study in the Psychology Department of the University of Michigan. Currently President of the Michigan Psychological Association, he is the author of Psychology and Aggression (1959), The Nature of Human Conflict (1965), The Concept of Human Development (1966), and a number of articles devoted to the study of hostility and violence on a personal and international scale. In addition, he is the director of a clinical training center for professional work with aggressive, delinquent, and emotionally disturbed boys. To counterbalance this unrelieved concern with conflict, he is a Field Selection Officer for the Peace Corps. 
B IRTH control may ultimately be the only trustworthy way to limit the amount of violence on this planet. Throughout history we have tried to reduce the human potential for violence by killing as many of our fellow men as we could, but we are falling behind in the task. Somewhere, between these extremes of was and never was, mankind still seeks a middle ground on which to stand without fear and trembling. The human condition is this: we can control violence in some of the people all of the time; we can control violence in all of the people some of the time; and we have failed throughout history to control violence in all of the people all of the time.

Perhaps violence involves so much primitive joy and raw gratification that the quest for its absolute control is nothing but a fool's errand. It may well be that only the long-term evolutionary alteration of humankind will produce a level of wisdom and restraint sufficient to banish assault as a means of communicating feelings to one's fellow man. It is equally possible that man has strayed from basic truth, has been corrupted by civilized living, and can only rediscover peaceful coexistence by examining the ways of our more primitive brethren-the animals.

\section{Violence-Fang and Claw Style}

An ancient adage states that man is distinguishable from animals primarily by his capacity for making trouble for himself. While this may be a somewhat cynical view of the condition of Homo sapiens, it remains true that in moments of despair about human violence we wistfully search the animal kingdom for moral and ethical guidance. Ever since Rousseau, we have suspected that the human condition is one depraved by the baleful influence of highrise crowding, megalopolis, breakneck speed, and the unremitting clamor of industrial society. In the earthy simplicity of species less complex than our own, we have sought a sign that there is hope for mankind. In simplicity there may indeed be truth, but it is wildly improbable that the anthill, beehive, or monkey colony has much to teach modern, interplanetary, atomic man straining to burst the bonds of time, place, and person. Yet, there are some basic observations of animal life reported by Scott ${ }^{1}$ that are worth underscoring. Scott insists, for example, that our classic stereotypes of animal behavior simply do not square with the facts. Wolves, for example, are regularly maligned; yet, the "traditional slinking, slavering, and treacherous animal of fiction corresponds only to the behavior of a wolf that has been recently trapped and is extremely frightened." Wolf packs, in a natural setting, live peacefully and co-operatively once a means of social control of aggression is established.

Among dogs and wolves, the principles of dominance and submission and of territoriality serve to limit the occasions on which violence occurs. Fighting is an instrument used to establish relative position in the social hierarchy, but it disappears once the rank-ordering is accomplished. Combat reappears, primarily, when the maturing young demand, from an aging social order, a new alignment of power and privilege.

The establishment of territories for foraging or nesting is another means of preventing conflict with rival groups. At the edges of these territories there are, regularly, the "border incidents" typical of human nations. Conflict, it seems, occurs most often at the point of intersection of one group competing with another.

Human bands have long sought to control and regulate violence by estab-

${ }^{1}$ J. P. Scott, "The Anatomy of Violence," The Nation (1965), pp. 200, 662-666. 
lishing territoriality (the nation-state) and by dominance and submission (power politics). Yet, the yield has been no more than continuous assaultive conflict and a history of civilization that is writ excessively large with dramatic accounts of senseless "heroism." Scott suggests that, at least in puppies, methods of rearing the young can foster gentility in the mature animal. $\mathrm{He}$ has demonstrated the truth of this assumption by raising five hundred puppies while only once being bitten. His method was simple: the puppies were never punished; they were hand-carried from place to place from birth; and, whenever they appeared aggressive, he rendered them helpless by hoisting them off the floor with a firm grip under the belly. This method required consistent but gentle restraint of aggressiveness early in life; he reports that it worked, and he suggests that, with some modification, these methods would produce comparable gentility in human beings.

While techniques of child-rearing are important contributors to the final shape of adult behavior, they cannot be considered in isolation from some measure of the organized-disorganized status of the society to which the individual must adjust. As Scott indicates, in an organized, highly structured, stable society the "social animal" is peaceful and cooperative; in a society that is disorganized and in transition, he is capable of the worst of destructive and violent behavior. Man's animal nature is a feeble excuse for violence; a more reasonable explanation is that the seemingly senseless violence of humans may be one of the costs of urban living. In the neglected center of our crowded cities the young, unmarried, unemployed male product of a broken home tends to be a prime source of the purposeless assault of one human on another. Yet, when individuals are driven to seek out kindred restive souls and to construct of them groups with a common hostile purpose, we have all the necessary ingredients of violence and defiance of social control.

Studies of the animal kingdom have a limited usefulness in expanding our grasp of the human condition. At best, the lives of social animals are only an approximate fit to that period in human life when the young child is without the tool of language and must rely solely on primitive methods for expressing aggression. As the child's capacity for verbal, abstract, and symbolic responses increases, the comparison of animal and man no longer contains either truth or relevance.

\section{The Creation of Violent Individuals}

The monster created by the legendary Dr. Frankenstein had to be destroyed because, having been spared the psychological trials and tribulations of childhood, it failed to learn alternative, nonviolent ways of reacting to frustration. In every known culture, history has been mute witness to the unremitting production of generation after generation of Frankensteinlike citizens. The methods vary, but the prime ingredients of this bitter stew of physical destruction of one man by another are recognizable even without a written recipe.

How do parents in any culture deliberately fashion a social Frankenstein? It is not a task easily accomplished since there is resiliency to youth that resists even the most horrendous of child-rearing circumstances. Yet, the steps parents must take are fairly direct, if not simple.

\section{Step 1: Have no love for the child.}

Love is a mercurial element that can vitiate the best of malicious intentions. Love topples what hate constructs. Love undermines rejection, softens the sting of anger, and dulls the edge of rage. Love fashions a protective cocoon that 
shelters the individual from the full force of the blows of fate. Love is insidious, and its workings are invisible to the eye. When love is absent, the child becomes an object like any other-an object to be used or misused as the needs of the parents dictate.

\section{Step 2: Shape the child's view of the world and people.}

Reward and punishment are the most useful tools for this purpose. The selective reward of some natural responses, coupled with the punishment of others, can underscore particular dimensions of personality at the same moment that it selects others for exclusion. If selective reward and punishment are begun early enough, continued for a sufficient length of time, and meshed subtly with an unmistakable parental example, the child will grow to maturity with a fixed and immutable perception of what constitutes truth and reality. The world view of the inexperienced and only partly comprehending child inevitably contains the image of the dominant parent whose philosophy of life and reaction to mankind get reflected in the basic fabric of the child's developing psychological life. Parents need only act as an interpretive filter of the real world; the selective experiences to which the child is exposed and the selective interpretation of these by the parents work together to fashion a child with a unique and highly personalized view of world affairs.

\section{Step 3: Reinforce preferred behavior while rationalizing it.}

The child must be totally convinced that his reactions to people and the fashion in which he treats them are natural, reasonable, correct, and not monstrous. Essentially, an extremist philosophy must pulse through the veins of the individual if violence is to lose its menacing aspect and become a necessary means to an absolutely essential end. The child must learn that in a jungle only savages survive. Addiction to violence on a personal, small-group, national, or international level must either be rewarded more often than it is punished or the punishment must seem undeserved and produce even greater dedication to a lethal life style. Violence needs an end to justify its means, and if the child can come to believe that his aggressive actions have a rational base he will, in times of high anxiety, become predictably violent as a means of solving problems.

Western society has always given lipservice to the belief that the end does not justify the means. It is an interesting ethical notion, but in real life mortals rarely live by such an unworkable dictum. Perhaps the production of a Frankensteinlike monster requires simply a conscious reversal of the "means-ends" ethic such that the emerging leader does as people do rather than as people say ought to be done. As far as the power-hungry individual is concerned, any ethic is defensible if it produces success.

How, then, do education and methods of child-rearing produce docile, nonaggressive, nonviolent adults? It is done, most often, by taking advantage of the dependent, helpless nature of the growing child. A set of expectations is established for the child, and a model is outlined of the kind of person he must strive to become. Then, the average child is exposed to pain, fear, deprivation, and isolation from others if he behaves in a nonacceptable manner. At the same time, he is praised and rewarded for approved behavior. These externally applied punishments produce, in the human animal, psychological reactions of guilt, fear, anxiety, a sense of loss and alienation from others, and feelings of rejection. It is from these 
internal emotional experiences that the child's self-image and self-esteem are formed.

This simplified schematic view of human development has one very serious limitation. The psychological reaction of the child to the internal and external events and pressures in his life is not always a direct or straight-line arrangement in which stimuli $X$ predictably produces reaction $Y$. The psyche of the child is not a mechanical system in which a known amount of push is automatically counterbalanced by a fixed amount of pull. Human beings are capable of distorting reality into shapes and forms that have a nightmare quality about them; human beings "process" their reactions through a complex psychological apparatus that allows seemingly incompatible and opposite reactions to issue from what appear to be identical, or at least similar, life circumstances.

Hollywood was so enthralled by the discovery of this psychological fact that it produced an appalling series of Grade$B$ movies in which the central theme was always the same-of a pair of siblings, one became a priest and the other, a gangster chieftain. The dramatic conflict between the two and the puzzling suggestion that both had issued from the same seed and the same squalid environment provided the dramatic denouement of the film. The psychological truth, of course, is that each individual is unique and that the "environment" is an inert substance until it is mixed with the volatile chemicals of a particular and peculiar psychological structure and stirred briskly by fate. Thus, the five-and-ten-cent variety of psychological generalization about the "mentality" of world leaders is, typically, grossly and frighteningly in error. Producing two psychological peas in a pod is beyond the capability of any known science.

\section{GrowiNg UP VIOLENT}

Violence on a planetary scale ought to be the most frightening possibility any of us could imagine; yet, our immediate anxieties are most often triggered by reports of teen-agers and young persons rioting across the face of the land. The dynamics of group violence among teenagers can be instructive of violence in other groups, as the kind and quality of organization of basic impulses, rather than the fact of teen-agedness, is the key to group violence.

According to the psychotherapist Rhoda Lorand, groups of young people riot as one means of dealing with a collection of personal and social pressures for which no other workable outlet is provided by the society-pressures such as a lack of confidence in their own masculinity, a need to discharge sexual excitement, or a deep-seated hostility toward parents and the adult model dictated by society. This analysis of the impulses expressed in "group acting-out" of basic problems and urges may or may not be accurate, and in no instance could we blithely assume that such an interplay of dynamic forces is typical of all members of a mob. Our concern is less with the personal dynamics of the individual members of a mob than with the chemistry of how these individual patterns of behavior get translated into violent group action.

The loosely federated mass of young people at a jazz festival or resort areaeach of whom is there because he anticipates that "that's where the action is"-needs only the addition of alcohol to begin the transformation from mass to mob. It was once said that an individual's conscience is best defined as that part of the personality soluble in alcohol. As alcohol dissolves inhibitions, those persons in the crowd with the least self-confidence, the least self-control, and the greatest need to "be some- 
one" become visible as they impulsively act out their problems in a primitive, childish, and aggressive fashion. These first daring, violent, or defiant outbursts surge through the milling crowd and strike a responsive chord in a second wave of young persons who, stimulated by seeing in action the inclinations, urges, and impulses they themselves have barely been able to contain, soon join the melee. And they join it with a vigor that outdoes the initiators. The members of this second wave of violence are unaware that the search for an excuse (someone else started it) for the open expression of violence is what has led them to be an "innocent" bystander at the scene of the action. Statistically, these innocent bystanders are most numerous, and they form the bond between a series of isolated incidents and the final mob ugliness.

Shortly, the fingers of riot reach out to the remaining onlookers-young people who now and then slip out of character and do foolish things when swept along by the tide of excitement that washes over their usually well-controlled impulse systems. It is at this point in time that the thinness of the veneer of civilization becomes most apparent. What we learn from history is that there never existed a time free of cruelty and violence and that any age is capable of becoming the worst that mankind has ever known, once the veneer of self-control is removed.

\section{A Time of Juveniles}

Eric Hoffer observed that "history is made by men who have the restlessness, impressionability, credulity, capacity for make-believe, ruthlessness, and selfrighteousness of children." 2 He suggests that it is a reasonable assumption -given the average life expectancy of past eras-that the invention of the

${ }^{2}$ Eric Hoffer, "A Time of Juveniles," Harpers, Vol. 230 (June 1965), p. 238. wheel and the calendar, the chivalry and romanticism of knights in armor, and the savagery of every recorded historical epoch may well be the work of the "juvenile mentality." Even the ranks of elders may be populated by persons who grew older but never grew up. Perhaps whole societies can come to act and think like juveniles if they are directed by leaders who personally epitomize this mentality and capitalize on the promise of unfettered impulse expression for all. The drums, the bugles, the uniforms, and the posturings of humanity - the deadly serious playingof-soldiers-appears in every age. Hoffer suggests that the juvenile turn of mind can be produced in an otherwise mature adult whenever that adult-be he immigrant, deprived citizen, civilian becoming soldier, or serf becoming free man-finds himself enmeshed in a mode of existence or state of in-betweenness of the adolescent. Perhaps the state of in-betweenness is the devil, and, perhaps, we are witnessing Hoffer's time of juveniles reborn. A society that must call out the National Guard in order to control its youth is an unappetizing society, indeed.

There is a quotation from the psychologist, Shakespeare, that contains the nub of difficulty in our attempt to erase violence.

First SERVANT: Why then we shall have a stirring world again. This peace is nothing, but to rust iron, increase tailors, and breed ballad makers.

Second SeRvant: Let me have war, say I; it exceeds peace as far as day does night; it's spritely, awaking, audible, and full of vent. Peace is a very apoplexy, lethargy; mulled, death, sleepy, insensible. . . .

\section{Shakespeare, Coriolanus}

\section{Managing the Medusa}

If violence is a function of complicated individual psychic processes, what can be done to manage the various forms in 
which it will rear its ugly head? It would be unrealistic to hope that childrearing procedures will ever be systematized and regulated by a controlled educational process designed to eliminate violence in cultures the world over. Societies of every sort will continue to supply the world with potentially violent citizens. The challenge is to manage the expression of aggression in adults who can no longer be controlled by the simple devices of childhood.

Violence tends to be a pastime of the young, and no society has succeeded in the search for an adequate substitute for it. William James' suggestion of a Moral Equivalent of War exactly describes the dimensions of the problem we face:

For the young, life needs to be defined in terms of the strenuous, the vivid, the intense. Life is to be conceived in such heroic terms that, in comparison with it, the heroism of war will offer no charms. It is doubtful whether a peaceful way of living will be achieved for modern man in terms of the traditional hymn writers' conception of peace as a region of lilies in the green pastures beside a murmuring brook. The old, the sick, the tired can be charmed by such visions; the young, the tough, and the resolute cannot. They will have their danger; they will have their struggle against obstacles. ${ }^{3}$

The preferred means of managing violence-prevention-may also be only a pipe dream. Fritz Redl once said that prevention, in its simplest form, means do not poison the soup. Thus, the prevention of violence may require correction of the conditions that produce the frustration that finds its outlet in assault and physical injury. Prevention, at another level, means detecting those among us most subject to uncontrolled violent expression and altering their personal adjustment or life circum-

\footnotetext{
${ }^{3}$ William James, Memories and Studies (1911).
}

stances-keeping the socially sick from becoming even sicker. To date, the best we seem able to accomplish is a kind of fire-brigade psychology in which we get to the conflagration shortly after the barn has burned down.

We cannot prevent what we cannot comprehend, and the older generation has yet to understand that times are different-that their musty memories of their own youth are a confused guide to the future. We have become the unwilling victims of the speed with which cultural change is taking place and we have become an Uncomfortable Generation. What has been lost to us is the comfort of slow-motion change that once gave us enough time to adjust, adapt, and come to terms. We have lost sympathy with the needs, anxieties, and frustration of the modern young and have forgotten that, throughout history, violence has been an anguished outcry of the hopeless, the frightened, and the insecure. To prevent is not the same as to stifle or ignore. We must find a means to render less alien this new generation, the placard-bearing, social-protesting, civilly disobedient segment of our social fabric.

\section{The Excuse for Vtolence}

Violence has always cloaked itself in the garments of some means of making it legitimate. In defense of violence, man has insisted that he was provoked beyond all human endurance; he has stated that he was not responsible by reason of insanity; he has pointed out that he acted only in self-defense; he has claimed that honor and manhood required violent response; he has maintained that he never intended to produce the outcome that occurred; he has said that what he did was for the ultimate good of society; and he has felt, if not said, that his actions were inescapably necessary given the situation in which he found himself. Theoretically, 
these reasons are an inadequate apology for human violence; in real life, these explanations are a valuable catalogue of excuses for destruction of one's fellow man.

Every society manages to teach a certain proportion of its members that these reasons for violence are acceptable and sensible explanations for recourse to injury of one's fellow man. If we teach some of our young that nonviolence is a luxury to be afforded only when conflict is not intense, then violence will never be dropped from the repertoire of human responses because, in certain circumstances, crime does pay, and may even be pleasurable. Physical assault too often produces exactly the outcome for which it was designed. Children bully one another and get away with it; adults threaten one another and achieve their goals; parents encourage violence in their children in conscious and unconscious ways; society rewards violence if it is conducted in good taste and is a means to a socially agreed-upon end; and subtle forms of social blackmail have long been an important aspect of man's interpersonal relations both on an individual and international level.

\section{VIOLENCE AND LEADERSHIP}

Mob violence, while distressing, and often fatal when it reaches its frenetic, fever pitch, remains a fairly isolated and infrequent event. Our anxiety is misplaced if it dwells for long on mob destruction, because the primary issue to be resolved is that of the violent leader who stimulates to action the impulses of those who would be less violent if not provoked.

If the urge to power among the mature is substituted for the beery motivation of the young, we can assemble a fatal equation. Political violence is far more dangerous than the panty-raids of the young. Our larger and more com- plex cultures demand cultured and sophisticated forms of violence in the service of power; the less "developed" the national unit, the more convenient and comfortable it is to wear the shroud of raw and apparent violence. It is in the setting of an emerging country that the leader makes his most visible contribution to the aggressive course of human affairs, but his influence is no less real in sophisticated cultures.

The leaders of people do not issue from the common mold of men; they tend, rather, to be drawn from among those deviates from the average whose personal charisma matches closely the needs and spirit of the times. Leaders with the unique ability to draw the human race willingly down the path to its eventual destruction must-in this view of humanity - have assembled a collection of personal characteristics and ways of behaving that fit the temper of the times and match the age in which they live. The nature of their developing years is a critical factor in understanding their response to the state of the world.

Despite the insistence of some theorists that the complex and highly interdependent organization of society acts to emasculate the forceful leader and render him powerless, it must be noted that even the advice and counsel of political associates must finally be shaped into a decision by one man. In truth, leaders rarely surround themselves with followers who are openly critical of their personality, life style, and decision-making techniques; leaders tend, rather, to establish a decision-making environment with a great deal of builtin consensus. The violent leader assures himself at least of sympathy and support and, often, of carte blanche for his actions. In so doing, the leader is less the victim of bad advice from others than he is the manufacturer of final consensus. 
Thus, group violence--at either the mob or the national level-has a series of preconditions which weld the needs of the group to the personality and psychological structure of the leader. These psychological forces become an inseparable part of the current political and national conditions that define the direction that events will take. The conclusion stressed here is that the comprehension of individual or group violence will continue to be a mystery if the form of development of human personality and the form to which human psychic structure can be modeled are treated as nothing more than an annoying gadfly pestering the concept of large-scale violence.

The complexity of the human psyche has made it so forbidding an area of exploration that modern theorists have discounted human personality as an important influence in the affairs of mankind. It is, indeed, an alien concoction and one not easily digested by the politico-economic-sociological theorists of this generation. Yet, denying that the psychological nature of man has relevance in understanding human violence has produced only a bankrupt and barren vision of the future of humanity. Man's psychic nature cannot remain an unknown in the equation of violence or we will find ourselves presiding over the dissolution of the human race.

In the course of development of the hostile human being destined for leadership, we see an organism fashioned to perceive a world composed primarily of threatening elements-threatening to him as a person and threatening to his conception of the way things ought to be in the world. The threat so visible to such a person is reacted to rapidly, intensely, and violently. Thus, his violent response happens easily, it happens often, and it needs little provocation. Faced with threat, the aggressive leader has few alternative forms of response at his command and, being incapable of tolerating stress, he falls back rapidly on the only response that has served him faithfully in the past. Cornered, he is incapable of a rational judgment free of the urge to aggrandizement or the impulse to strike out and destroy those he perceives as plaguing him with anxiety.

We are rapidly approaching that point in time when the fate of humanity will be cradled in the sweating palm of just such a person. At this fatal juncture in the history of man we may pay sorely if we fail to recognize that violence and human development are twin facets of the same basic process. The dehumanized study of violence is very much like pretending that "things" and "abstract conceptions" of political-economic-social events have an existence all their own, and should be called "living" systems.

I think that the historians of 1984 will conclude that "the proper study of man is mankind." I am convinced that an understanding of the pattern of human development is the key that will one day suggest a workable plan for controlling violence in Homo sapiens. 